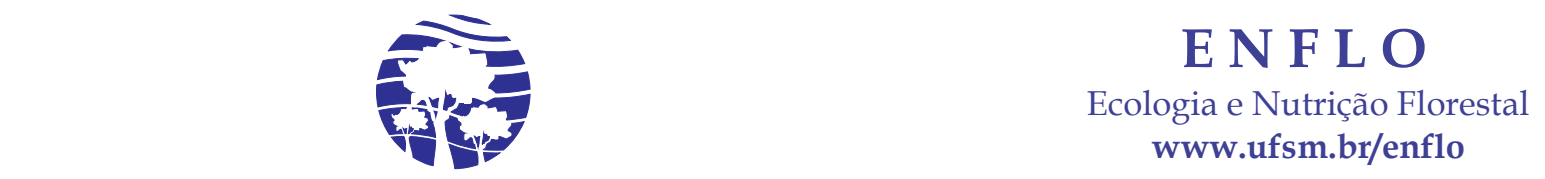

\title{
Densidade de Fluxo de Fótons (DFF) em um sistema de Integração Lavoura-Pecuária-Floresta $(\text { ILPF })^{1}$
}

\author{
Luanna Elis Guimarães ${ }^{2}$; Carlos de Melo Silva-Neto ${ }^{3}$ Francine Neves Calil ${ }^{4}$
}

\begin{abstract}
Resumo: Este estudo foi realizado em um sistema de produção integrado lavoura-pecuária-floresta no município de Cachoeira Dourada, Goiás, Brasil. A pesquisa colabora para um melhor entendimento da interação planta-ambiente, esta foi realizada com o objetivo de analisar a entrada de luz em dois períodos diferentes (estação seca e chuvosa). Para a coleta da Densidade de Fluxo de Fótons (DFF) $\left(\mu \mathrm{mol} . \mathrm{m}^{-}{ }^{2} \mathrm{~s}^{-}{ }^{1}\right)$ foi utilizado dois sensores de quanta LI-250 A, Li-cor Inc., USA, na faixa fotossinteticamente ativa. A coleta foi realizada de hora em hora, com início às $9 \mathrm{~h} 45 \mathrm{~min}$ e término às $17 \mathrm{~h} 45 \mathrm{~min}$. Coletou-se o DFF controle - a pleno sol, e as demais coletas foram realizadas em quatro pontos: (1- no centro do renque de árvores, 2 - a $5 \mathrm{~m}$ do renque, 3 - a 10m do renque e 4 - a 15m do renque), sendo que em cada ponto se obteve mais 4 repetições. De acordo com os resultados obtidos se verificou que houve diferenças entre os pontos escolhidos, sendo o ponto 10 e 15 metros com maior recebimento de faixa de Radiação Fotossinteticamente Ativa (RFA). Portanto, o sistema Integrado Lavoura-PecuáriaFloresta (ILPF) não reduziu a Densidade de Fluxo de Fótons (DFF). A maior DFF foi verificada no período de seca, porém, a maior variação da DFF foi encontrada no período chuvoso. Quanto maior à distância em relação aos renques, com eucaliptos, maior à incidência de radiação solar.
\end{abstract}

Palavras - chave: Luminosidade; Produtividade; Fotossíntese; Agrossilvipastoril.

\section{Photon flux density in a crop livestock forest system}

\begin{abstract}
This study was conducted in a crop livestock forest system in Cachoeira Dourada, Goiás state, Brazil. Aiming to contribute to a better understanding about plant-environment interaction, this study had as objective to analyze light input in two different periods (dry and wet season). For photon flux density (PFD) measurement, two quanta sensors (LI-250 A, Licor Inc., USA) were used, in photosynthetically active band. Data collection was done in each hour, starting at 9:45 and ending at 17:45, and also collected the control to full sun, and other collections in: ( 1 in the center of the row of trees, 2 - at $5 \mathrm{~m}$ of hedgerow 3 -at $10 \mathrm{~m}$ of hedgerow 4 - at $15 \mathrm{~m}$ of hedgerow), in each point 4 replications were obtained. According to the observed results, it was possible to verify that there were differences among the chosen points, being the points 10 and 15 meters the ones that receive the most range of PAR.most receiving range (PAR). Therefore, CLFS system did not reduce photons flux density. Highest PFD was verified during the dry season however the highest variation was verified in the wet period. The greater the distance from the rows with trees, the greater the incidence of solar radiation.
\end{abstract}

Keywords: Luminosity; Productivity; Photosynthesis; Agroforestry.

\footnotetext{
${ }^{1}$ Recebido em 04.02.2016 e aceito para publicação como artigo científico em 17.10.2016.

${ }^{2}$ Bióloga, M.Sc., Doutoranda em Agronomia - Programa de Pós Graduação em Agronomia - Produção Vegetal (PPGA/UFG), Universidade Federal de Goiás. E-mail: <luanna.meioambiente@gmail.com>.

${ }^{3}$ Biólogo, M.Sc., Doutor em Agronomia - Produção Vegetal (PPGA/UFG), Universidade Federal de Goiás. E-mail: <carloskoa@gmail.com>.

${ }^{4}$ Engenheira Florestal, Dra. Professora Titular da Escola de Agronomia, Universidade Federal de Goiás. E-mail <fncalil@gmail.com>.
} 


\section{Introdução}

A Integração Lavoura-Pecuária-Floresta é caracterizada por diversificação, rotação, consorciação ou sucessão das atividades agrícolas e pecuárias dentro da propriedade rural de forma equilibrada, compondo um mesmo princípio, de tal maneira que há benefícios para ambos. Permite ainda vantagem, como, a exploração econômica do solo durante todo o ano ou, pelo menos, na maior parte dele, favorecendo, com isso o aumento da oferta de grãos, de fibras, de carnes, de leite e de agroenergia a custos mais baixos devido ao sinergismo que acontece entre os componentes silviculturais e de pastagem (ALVARENGA et al., 2010; ABREU et al., 2016).

A luz é a fonte elementar de energia associada à fotossíntese e aos fenômenos morfogenéticos, sendo assim, um dos influenciadores do crescimento e do desenvolvimento vegetal (GAZOLLA-NETO et al., 2013). Dessa forma, a eficácia do crescimento pode estar relacionada à capacidade de adaptação das plantas as condições de luminosidade do ambiente, constituindo um crescimento satisfatório de espécies em ambientes com luminosidade baixa ou alta, atribuído à habilidade da espécie em ajustar rapidamente seu modelo de alocação de biomassa e seu comportamento fisiológico (DIAS-FILHO, 1999).

As plantas apresentam distintas respostas quanto à tolerância ao sombreamento, influenciando no crescimento e no desenvolvimento (PAEZ et al., 2000). As espécies arbóreas proporcionam certo sombreamento, que pode interagir de diversas formas com as espécies gramíneas, como, na diminuição da produção de biomassa da pastagem (ROZADOS-LORENZO et al., 2007; CALIL et al., 2016) ou no aumento do teor de proteína existente nas forrageiras (PACIULLO et al., 2011). O componente florestal exerce uma influência no sistema que depende de uma série de fatores, entre eles, as espécies vegetais empregadas e os espaçamentos instituídos na implantação do sistema (PACIULLO et al., 2011; LEMOS-JUNIOR et al., 2016).
Numa outra direção, a temperatura e a quantidade de luz disponível, junto com a água e os nutrientes do ambiente, determinam quando e quão rapidamente a folha pode fotossintetizar e até que ponto a planta cresce e tem probabilidade de sobreviver (GUREVITCH et al., 2009). Em função disso a disponibilidade de Radiação Fotossinteticamente Ativa (RFA) desempenha efeito na determinação de condições específicas de cultivo, pelo fato de ser o fator principal de regulação da fotossíntese, especialmente da assimilação de dióxido de carbono $\left(\mathrm{CO}_{2}\right)$ na abertura estomática e na síntese de clorofila (KOZLOWSKI et al., 1991).

Visando a colaborar para o melhor entendimento dos fatores abrangidos na interação planta-ambiente, analisou-se a entrada de luz em dois períodos distintos (estação seca e chuvosa), no sistema integrado de produção lavoura-pecuária-floresta, em Cachoeira Dourada, Goiás.

\section{Material e métodos}

\section{Caracterização da área}

O estudo foi desenvolvido no período de outubro de 2013 a abril de 2015, no município de Cachoeira Dourada, GO. A área experimental possui coordenadas geográficas centrais 18 29' 30 " S, longitude 4928 ' 30 " W e altitude de 459 metros em relação ao nível médio do mar.

De acordo com a classificação de Köppen e Geiger, o clima é considerado o Aw - clima tropical com estação seca de inverno (CARDOSO et al., 2015). A precipitação média anual é de 1.200 a 1.500 milímetros, concentrados entre o período chuvoso de outubro a abril. Quanto à distribuição das chuvas, a precipitação média anual está entre 1200 e $1600 \mathrm{~mm}$, concentradas em outubro a abril (estação chuvosa), variando em média entre 100 e $350 \mathrm{~mm}$. Enquanto na estação seca, que ocorre de abril a setembro, a média do índice pluviométrico varia de 0 a $100 \mathrm{~mm}$. A temperatura média anual é de $24,8{ }^{\circ} \mathrm{C}$, registrando a máxima de $35^{\circ} \mathrm{C}$, em setembro e a 
mínima de $21,9^{\circ} \mathrm{C}$, em junho (CABRAL, 2006).

Segundo Cabral (2006), predomina na região o Latossolos com horizonte "A" moderado e proeminentemente de textura muito argilosa e argilosa. Em pequenas áreas ocorre Argissolos, Nitossolos, Gleissolos Háplicos e Neossolos, que apresentam $\mathrm{pH}$ variando de 4,3 a 6,2. O local também possui elevado conteúdo de alumínio, baixa disponibilidade de macro e micronutrientes, reduzido conteúdo de matéria orgânica e fração argila, composta predominantemente por caulinita, goethita ou gibbsita (IBGE, 1983; EMBRAPA, 1999).

Implantação do sistema ILPF

O sistema de ILPF deste estudo possui uma área total de 9,45 hectares e sua implantação foi no mês de fevereiro de 2012. O sistema de integração é constituído pelo Eucalyptus urograndis (E. urophylla $x \quad E$. grandis) consorciado com a espécie forrageira braquiária (Urochloa brizantha (Stapf) Webster.). O proprietário tem como objetivo, para a madeira de eucalipto produzida, realizar seu primeiro desbaste com cerca de seis anos, tendo a finalidade de madeira para energia. $O$ corte final está previsto para quando a planta atingir quatorze anos, com a finalidade de uso da madeira para serraria.

O delineamento é formado pela expressão 4 $(3 m \times 3 m)+22 m$, sendo os renques formados por 4 linhas de plantas de E. urograndis no espaçamento de $3 \mathrm{~m} \mathrm{X} 3 \mathrm{~m}$. Entre os renques de arbóreas são 22 metros de cultivo da forrageira braquiária ( $U$. brizantha (Stapf) Webster.), ao todo são 8 blocos neste delineamento.

Para a implantação das espécies florestais e do primeiro cultivo anual foi realizado primeiramente o combate as formigas e aos cupins, em toda a área. Após, ocorreu o processo de gradagem na linha de plantio, sendo que, juntamente com essa operação aplicou-se a calagem e a adubação química ao solo, na linha do cultivo anual de soja, com a seguinte formulação: NPK 08-30-10 + 0,5\% de Zn, sendo aplicados $300 \mathrm{~kg} \mathrm{ha}^{-1}$. O plantio da soja (Glycine $\max$ L.) foi feito entre os renques de eucalipto
(22 metros). Em seguida, executou-se o plantio das mudas de eucalipto, que foram implantadas manualmente, no mês de janeiro de 2012. Após 20 dias do plantio do eucalipto foi realizada a adubação com $150 \mathrm{~g} /$ planta de NPK 08-30-10, através de covetas laterais, distantes $20 \mathrm{~cm}$ da planta.

Coleta de dados

A Densidade de Fluxo de Fótons - DFF ( $\mu$ mol $\mathrm{m}^{2} \mathrm{~s}^{1}$ ) foi medida com a utilização de sensores de quanta LI-250 A, Li-cor Inc., USA, na faixa fotossinteticamente ativa. Os sensores foram calibrados no decorrer das medições, sob a condição de pleno sol. Para cada medida tomada no sistema ILPF, outra medida era tomada, simultaneamente a pleno sol, próximo à área do ILPF estudado.

Os sensores a pleno sol e o móvel foram posicionados a um metro de altura do solo. Por medida de controle foi mantido o sensor nivelado horizontalmente com o auxílio de plataformas e estacas de madeira que foram previamente fixadas no local, conforme metodologia descrita por Felfili e Abreu (1999) e utilizada por Venturoli et al. (2012). Essa técnica permitiu, por comparação, quantificar a quantidade de luz que atravessa o dossel da árvore até a altura dos sensores e a Densidade de Fluxo de Fótons (DFF), que chegava as diferentes posições na pastagem.

Para as variáveis relacionadas à luz (DFF) foram utilizados os dados referentes ao período de amostragem realizadas em novembro/2014 (período de seca) e abril/2015 (período de chuva). As medidas foram coletadas entre às horas $9 \mathrm{~h} 45 \mathrm{~min}$ e $17 \mathrm{~h} 45 \mathrm{~min}$, em dias com céu predominantemente claro, sendo observado que na primeira coleta de dados era horário de verão (período seco). Cada medição foi realizada com 30 segundos de diferença para cada um dos 16 pontos amostrados. Esse procedimento foi repetido de hora em hora, durante o período de monitoramento.

As avaliações de irradiância foram realizadas com um ponto no centro do renque de Eucalipto (entre as quatro linhas de cultivo) e mais três 
pontos distribuídos a: 5, 10 e 15 metros, entre os renques (área com pastagem). O número total de repetições foi de 16 pontos, sendo ao todo quatro blocos analisados, ao qual cada bloco representa um renque + pastagem.

Toda amostragem de dados foi realizada em dois períodos distintos - época seca (novembro/2015) e chuvosa (abril/2015). Na estação seca, os dias avaliados eram ensolarados e sem nuvens, e na estação chuvosa, apesar de ensolarado, muitas nuvens cobriam o céu em determinados períodos ao longo do dia.

Para verificar a diferença de intensidade luminosa em cada posição amostral foi realizada regressão múltipla, com $95 \%$ de significância estatística, da diferença de intensidade luminosa do equipamento controle (ambiente externo ao ILPF) com os dos pontos avaliados no sistema ILPF. Para comparação entre a Densidade de Fluxo de Fótons média em diferentes áreas
(ILPF e pleno sol), nas diferentes estações (seca e chuvosa), foi realizado análise de variância com teste de comparação múltipla de Tukey com 95\% de significância estatística.

\section{Resultados e Discussão}

A Densidade de Fluxo de Fótons (DFF) para a avaliação a pleno sol variaram ao longo do dia de $2,23 \mu \mathrm{mol} \mathrm{m} \mathrm{m}^{-2}$ a $1622,4 \mu \mathrm{mol} \mathrm{m} \mathrm{m}^{-2} \mathrm{~s}^{-1}$. A DFF no sistema integrado de produção ILPF variou de $1,49 \mu \mathrm{mol} \mathrm{m}^{-2} \mathrm{~s}^{-1}$ a $1915,6 \mu \mathrm{mol} \mathrm{m}^{-2} \mathrm{~s}^{-}$ 1 , ambos valores foram obtidos no mesmo horário, sendo o menor valor às $17 \mathrm{~h} 45 \mathrm{~min}$ e o maior valor às $13 \mathrm{~h} 45 \mathrm{~min}$. As maiores DFF foram verificadas no período seco, e as menores no período chuvoso. Entretanto, foi observada na época chuvosa maior variação do DFF durante o período avaliado ao logo do dia (Figura 1).

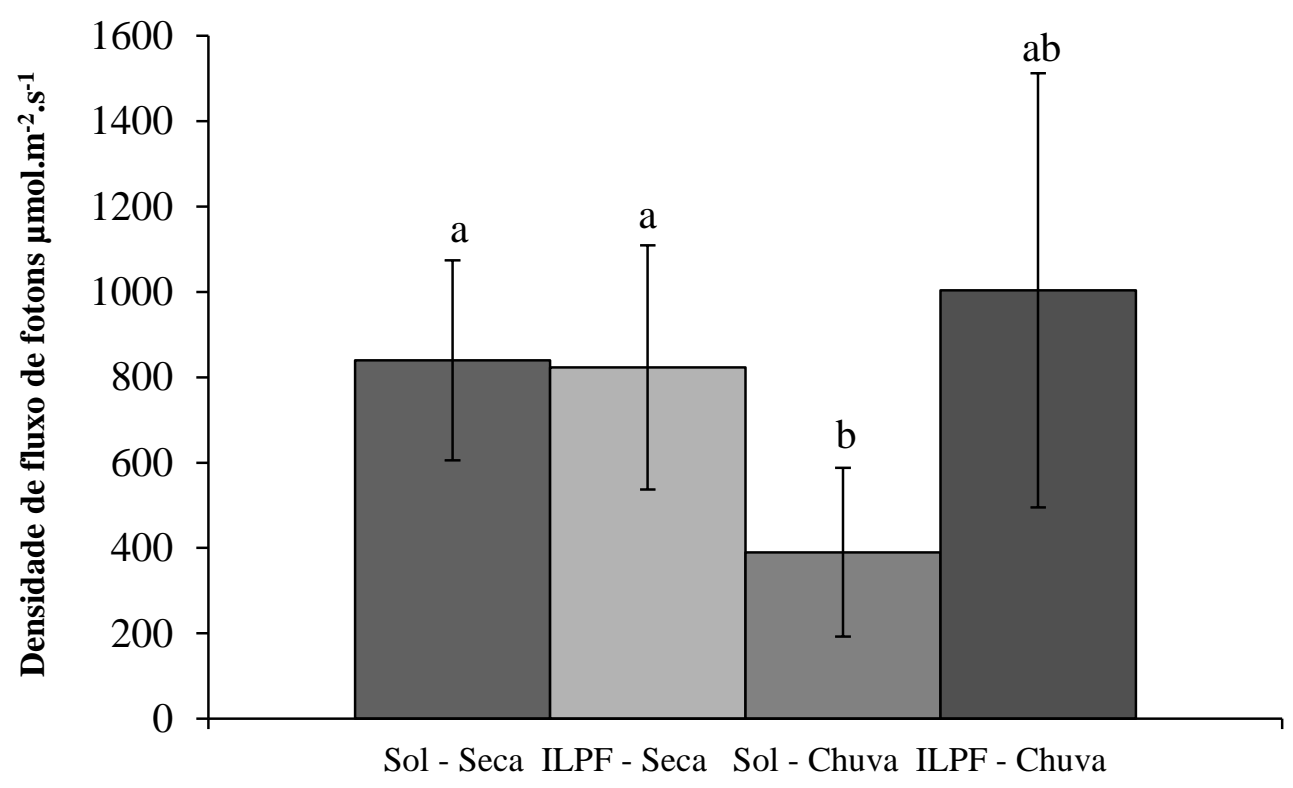

Figura 1 - Médias da Densidade de Fluxo de Fótons - DFF no sistema integrado de produção ILPF e a pleno sol, nas estações seca e chuvosa (Teste de Tukey com letras diferentes indicando diferença estatística, $\mathrm{p} \leq 0,05$ ).

Figure 1 - Average of photon flux density - PFD for the evaluation of Light ILPF and for evaluation the full sun in two seasons dry and rainy (Tukey test with different letters indicate statistical difference, $\mathrm{p} \leq 0,05$ ).

Neste estudo se observou que o período de seca, mesmo sendo o período de maior preocupação dos pecuaristas no centro-oeste brasileiro, foi o que apresentou maiores valores absolutos de DFF, ocasionando uma maior capacidade fotossintética. Para a época de seca, 
Andrade et al. (2014) afirmaram que há menor nebulosidade na atmosfera, ou seja, poucas nuvens cobrindo o céu, como também onde se registra as altas incidências de radiação solar. Pedreira e Pedreira (2007) estudando fotossíntese foliar de Urochloa brizantha chegaram ao entendimento que ocorre o aumento da fitomassa em cultivos, tal fato depende principalmente do desenvolvimento da área foliar (dossel), ressaltam ainda os autores que a interceptação luminosa está associada à altura e ao Índice de Área Foliar (IAF) em todas as estratégias de pastejo que eles avaliaram.

Observando a pastagem de $U$. brizantha arborizada, Rakocevic e Ribaski (2002) registraram respostas morfológicas, provocadas pelo regime de radiação solar incidente na pastagem, sendo que a restrição de radiação solar causada pelo sombreamento somente se tornou crítica para a fotossíntese quando se estabeleceu estresse hídrico, acentuando, com isso, a competição interespecífica deste povoamento. Demonstrou tal estudo que em períodos secos há a possibilidade de ocorrer diminuição da capacidade fotossintética, mesmo havendo maior índices de Densidade de Fluxos de Fótons (DFF).

O capim-braquiária do gênero Urochloa apresenta ajustes morfofisiológicos, em resposta ao sombreamento, tais como acréscimo, da relação parte aérea/raiz, da área foliar específica e da taxa de alongamento foliar, o que lhe permite mantimento da produtividade, mesmo em condições de limite de luminosidade (GUENNI et al., 2008; PACIULLO et al., 2008).

De acordo com as análises estatísticas realizadas para este estudo, não houve diferença entre as estações/períodos (seca e chuva), como também, não houve diferença entre os horários de coleta. Por outro lado, ocorreram diferenças nos pontos amostrados, sendo os pontos com maior percentual de incidência luminosa aqueles situados mais distantes aos renques com eucaliptos (10 e 15 metros do renque) (Figuras 5 e 6).

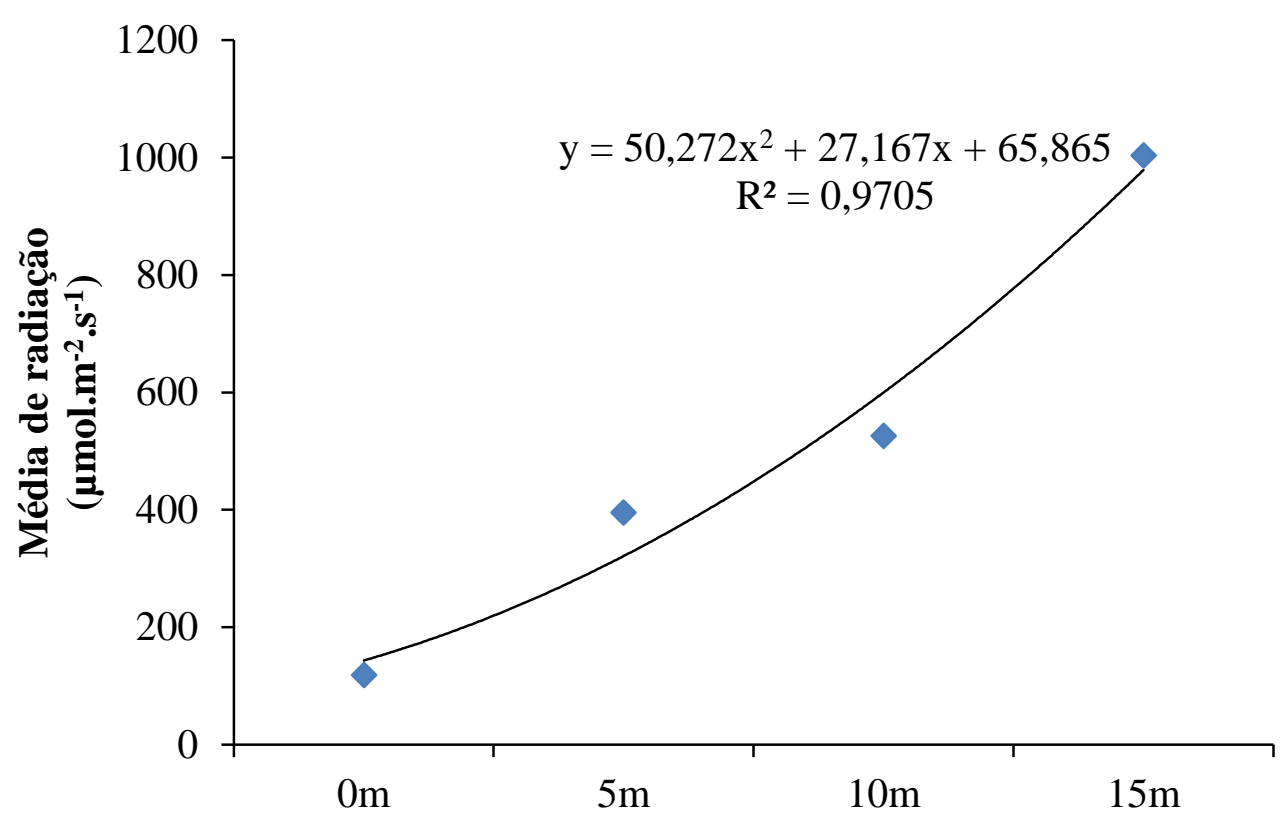

Figura 2 - Incidência solar em função da distância ao renque com cultivo de eucaliptos no período de seca em um sistema de produção Integrado Lavoura-Pecuária-Floresta.

Figure 2 - Sun incidence regression between the points sampled in the dry season in a system of crop-livestock-forest integration. 
Constatou-se a ocorrência de uma regressão linear de incidência solar a cada metro em direção ao centro da pastagem, no período de seca (Figura 2). Já, no período de chuva o aumento não foi linear, resultando em uma menor incidência solar, quando comparado com a época de seca (Figura 3).

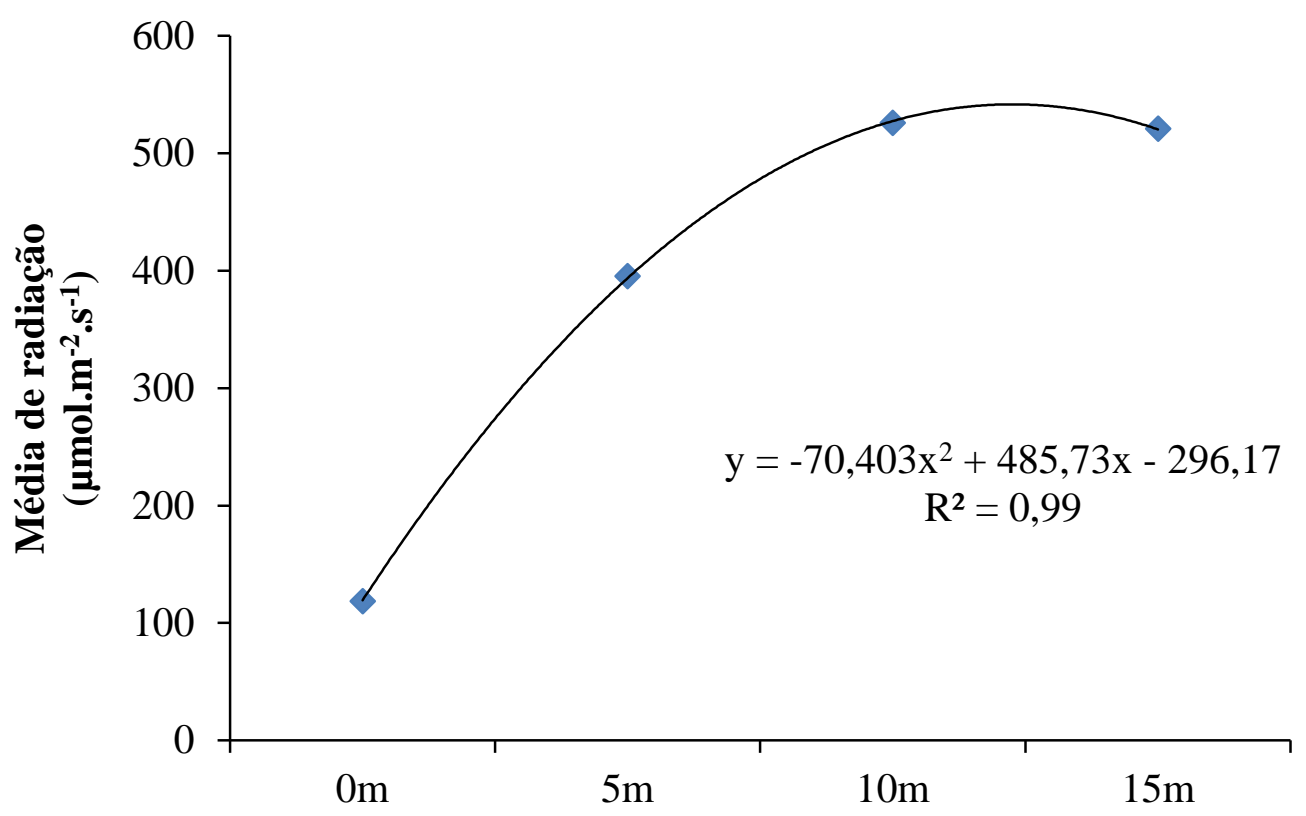

Figura 3 - Incidência solar em função da distância ao renque com cultivo de eucaliptos no período de chuva em um sistema de produção Integrado Lavoura-Pecuária-Floresta.

Figure 3 - Sun incidence regression between the points sampled in the rainy season in a system of crop-livestock-forest integration.

Conforme o esperado, o ponto de coleta mais distante aos renques de eucaliptos apresentou maior DFF para ambas as épocas avaliadas (seca e chuva). Gurevitch et al. (2009) explanaram que quanto maior à incidência de luz, para captura das plantas, maior será a taxa fotossintética. Pode-se inferir com este trabalho que as plantas de $U$. brizantha situadas mais ao centro, entre renques (10 e 15 metros), receberam mais DFF, e, portanto, podem apresentar maior taxa fotossintética e aumento de IAF (fitomassa). Os resultados corroboram com os estudos de Porfírio-da-Silva (2001), que registraram um incremento do Índice de Área Foliar (IAF) das forrageiras nas regiões centrais, entre os renques de árvores, embora tal estudo tenha observado menor incidência solar no período chuvoso.

$\mathrm{O}$ limite de radiação mínima para a sobrevivência das plantas vasculares, em geral está entre $0,5 \%$ - $1 \%$ da radiação solar total incidente (LARCHER, 2000). Oliveira et al. (2007), estudando o efeito da radiação em diferentes arranjos que compunha sub-bosque de eucaliptos e de pastagem em sistema agrossilvipastoril, concluíram que em maiores espaçamentos de entrelinhas de árvores ocorreu maior luminosidade e por mais tempo. Rodrigues et al. (2013), avaliando sistemas agrossilvipastoris, identificaram que os arranjos espaciais influenciam a produção e o valor nutritivo do capim-braquiária, sendo que o arranjo espacial de $20 \times(3 \times 2) \mathrm{m}$, avaliado por eles, proporcionou melhor produção de massa seca. Ainda o mesmo estudo prevê que os espaçamentos mais adensados de $9 \times 2 \mathrm{~m}$ ou $9 \times(2 \times 2) \mathrm{m}$ proporcionam melhor composição bromatológica com maiores teores de proteína bruta e menores teores de fibra em detergente 
neutro.

Estudos de modificações microclimáticas em sistemas silvipastoris com Grevillea robusta na região noroeste do Paraná, realizados por Porfírio-da-Silva (1998), apontam que a espécie arbórea atenua o fluxo de radiação fotossinteticamente ativa no sub-bosque, contudo tal fator não impede o aumento da produtividade de matéria seca (biomassa) da pastagem nas áreas sob as copas das árvores.

\section{Conclusões}

No sistema ILPF a maior DFF foi verificada no período de seca, porém a maior variação da DFF foi verificada no período chuvoso. Quanto maior à distância em relação aos renques com eucaliptos, maior foi à incidência de radiação solar sob a forrageira braquiária (U. brizantha (Stapf) Webster.).

\section{Agradecimentos}

Ao proprietário da Fazenda "Boa Vereda Abílio Rodrigues Pacheco"; ao Laboratório de Alometria e Inventário Florestal (LAIF/UFG), pelo empréstimo dos equipamentos necessários; a FAPEG - Fundação de Amparo à Pesquisa de Goiás; e ao CNPq - Conselho Nacional de Desenvolvimento Cientifico e Tecnológico, pela concessão de bolsa de pesquisa.

\section{Referências Bibliográficas}

ABREU, S. A. H.; ARRUDA, E. M.; BARROS, L. R.; ALMEIDA, R. F.; MARANHAO, D. D. C.; SILVA, V. L.; SILVA NETO, CARLOS DE MELO; FLORES, R. A.; CALIL, F. N.; COLLIER, L. S. Chemical attributes of the soil in agroforestry systems subjected to organic fertilizations. African Journal of Agricultural Research, v. 11, p. 2378-2388, 2016.

ALVARENGA, R. C.; PORFIRIO-DA-SILVA, V.; GONTIJO NETO, M. M.; VIANA, M. C.
M.; VILELA, L. Sistema Integração LavouraPecuária-Floresta: Acondicionamento do solo e intensificação da produção de lavouras. Informe Agropecuário, v. 31, n. 257, p. 59-67, 2010.

ANDRADE, A. M. D. de; MOURA, M. A. L.; DOS SANTOS, A. B.; CARNEIRO, R. G.; SILVA, R. S. da. Radiação fotossinteticamente ativa incidente e refletida acima e abaixo do dossel de floresta de mata atlântica em Coruripe, Alagoas. Revista Brasileira de Meteorologia, v. 29, n. 1, p. 68-79, 2014.

CABRAL, J. B. P. Análise da sedimentação e aplicação de métodos de previsão para tomada de medidas mitigadoras quanto ao processo de assoreamento no reservatório de Cachoeira Dourada-G0/MG. 2006. 211 f. Tese de Doutorado. Universidade Federal do Paraná, Curitiba, 2006.

CALIL, F. N.; BRANDAO, D. C.; LIMA, N. L.; BARBOSA, P. V. G.; CARVALHO, H. C. S.; LIMA, P. A. F.; DIANESE, M.; SILVA, R. T.; NASCIMENTO, A. R.; SILVA-NETO, C. M. Biomass and nutrition stock of grassland and accumulated litter in a silvopastoral system with Cerrado species. African Journal of Agricultural Research, v. 11, p. 3701-3709, 2016.

CARDOSO, M. R. D; MARCUZZO, F. F. N; BARROS, J. R. Classificação Climática de Köppen-Geiger para o Estado de Goiás e o Distrito Federal. Acta Geográfica, v. 8, n. 16, p. 40-55, 2015.

DIAS FILHO, M. B. Physiological response of Solanum crinitum Lam. to contrasting light environments. Pesquisa Agropecuária Brasileira, v. 32, p. 789-796, 1997- 2000.

EMBRAPA - EMPRESA BRASILEIRA DE PESQUISA AGROPECUÁRIA. Sistema brasileiro de classificação de solos. Rio de Janeiro, 412p.,1999.

FELFILI, J. M.; ABREU, H. M. Regeneração natural de Roupala montana Aubl., Piptocarpha 
macropoda Back. E Persea fusca Mez. em quatro condições ambientais na mata de galeria do Gama - DF. Cerne, v.5, n.2, p.125-132, 1999.

GAZOLLA-NETO, A. et al. Ação de níveis de luminosidade sobre o crescimento de plantas de maria-pretinha (Solanum americanum Mill.). Revista Brasileira de Biociências, v. 11, n. 1, 2013.

GUENNI, O.; SEITER, S.; FIGUEROA, R. Growth responses of three Brachiaria species to light intensity and nitrogen supply. Tropical Grasslands, v.42, p.75-87, 2008.

GUREVITCH, Jessica; SCHEINER, Samuel M.; FOX, Gordon A. Ecologia vegetal. Artmed, 2009.

IBGE - INSTITUTO BRASILEIRO DE GEOGRAFIA E ESTATÍSTICA. Projeto Radambrasil: Levantamento de Recursos hídricos. Folha SE 22 - Goiânia. V31. Geologia, geomorfologia, pedologia. Rio de Janeiro. 1983.

KOZLOWSKI, T. T.; KRAMER, P. J.; PALLARDY, S. G. The Physiological Ecology of Woody Plants. Tree Physiology, v. 8, n. 2, p. 213-213, 1991.

LARCHER, W. Tradução Carlos Henrique BA Prado. Ecofisiologia vegetal. São Carlos: RiMa, 2000.

LEMOS-JUNIOR, J. M.; Souza, K. R.; GUIMARAES, L. E.; OLIVEIRO, F. D.; MONTEIRO, M. M.; GONCALVES, R. A.; MELO-SILVA, CARLOS DE; LIMA, N. L.; Venturoli, F.; CALIL, F. N. Volumetric models for Eucalyptus grandis $\mathrm{x}$ urophylla in a croplivestock-forest integration (CLFI) system in the Brazilian cerrado. African Journal of Agricultural Research, v. 11, p. 1336-1343, 2016.

OLIVEIRA, T. D. et al. Produtividade de Brachiaria brizantha (Hochst. ex A. Rich.) Stapf cv. Marandu sob diferentes arranjos estruturais de sistema agrossilvipastoril com eucalipto. Ciência e Agrotecnologia, v. 31, n. 3, p. 748-757, 2007.

PACIULLO, D.S.C.; CAMPOS, N.R.; GOMIDE， C.A.M.; CASTRO， C.R.T. de; TAVELA, R.C.; ROSSIELLO, R.O.P. Crescimento de capim-braquiária influenciado pelo grau de sombreamento e pela estação do ano. Pesquisa Agropecuária Brasileira, v.43, p.917-923, 2008.

PACIULLO, D. S. C., GOMIDE, C. A. M., CASTRO, C. D., FERNANDES, P. B., MÜLLER, M. D., PIRES, M. F. A., ... \& XAVIER, D. F. Características produtivas e nutricionais do pasto em sistema. agrossilvipastoril, conforme a distância das árvores. Pesquisa Agropecuária Brasileira, 46(10), 1176-1183, 2011.

PAEZ, A.; PAZ, V.; LÓPPEZ, J. C. Crecimiento $\mathrm{y}$ respuestas fisiológicas de plantas de tomate $\mathrm{cv}$. Rio Grande en la época mayo-julio. Efecto del sombreado. Revista da Faculdade de Agronomia, 17: 173-184, 2000.

PEDREIRA, B. C; PEDREIRA, C. G. S. Leaf photosynthesis in Xaraés palisadegrass [Brachiaria brizantha (A. Rich.) Stapf. cv. Xaraés] and modeling canopy assimilatory potential under rotational stocking strategies. Revista Brasileira de Zootecnia, v. 36, n. 4, p. 773-779, 2007.

PORFÍRIO-DA-SILVA, V. Modificações microclimáticas em sistema silvipastoril com Grevillea robusta A. Cunn ex. R. Br. na região noroeste do Paraná. 1998. 152 f. Dissertação (Mestrado em Agroecossistemas) - Universidade Federal de Santa Catarina, Santa Catarina, SC, 1998.

PORFÍRIO-DA-SILVA, V. Arborização de pastagens como prática de manejo ambiental e estratégia para o desenvolvimento sustentável do Paraná. In: CARVALHO, M.M. et al. (Ed.). Sistemas agroflorestais pecuários: opções de 
sustentabilidade para áreas tropicais e subtropicais. Juiz de Fora: Embrapa Gado de Leite; Brasília: FAO, p.235-255, 2001.

RAKOCEVIC, M.; RIBASKI, J. Propriedades fisiológicas e estruturais de braquiária (Braquiaria brizantha Hochst. ex A. Rich) em consórcio com eucalipto (Eucalyptus citriodora Hook.) em um sistema silvipastoril no noroeste do Paraná. In: CONGRESSO BRASILEIRO DE SISTEMAS AGROFLORESTAIS, 4., 2002, Ilhéus. Sistemas agroflorestais, tendência da agricultura ecológica nos trópicos: sustento da vida e sustento de vida: Anais... Ilhéus: CEPLAC, 2002.

RODRIGUES, D. M.; DA SILVA, M. M.; DE ALMEIDA, L. S.; DE SOUZA, T. R.; YARED, J. A. G.; DE SANTANA, A. C. Agrobiodiversidade e os serviços ambientais: perspectivas para o manejo ecológico dos agroecossistemas no Estado do Pará. Revista Agroecossistemas, v. 4, n. 1, p. 12-32, 2013.

ROZADOS LORENZO, M. J.; GONZALEZ HERNANDEZ, M. P.; SILVA PANDO, F. J. Pasture production under different tree species and densities in an Atlantic silvopastoral system. Agroforestry Systems 70, 53-62, 2007.

VENTUROLI, F. et al. Regime de luz em uma floresta estacional semidecídua sob manejo, em Pirenópolis, Goiás. Revista Árvore, v. 36, n. 6, p. 1135-1144, 2012. 